Pacific Journal of Mathematics

BOUNDED ENTIRE SOLUTIONS OF ELLIPTIC EQUATIONS 


\section{BOUNDED ENTIRE SOLUTIONS OF ELLIPTIC EQUATIONS}

AvNER FrIEDMAN

Let

$$
L u=\sum_{i, j=1}^{n} a_{i j}(x) \frac{\partial^{2} u}{\partial x_{i} \partial x_{j}}+\sum_{i=1}^{n} b_{i}(x) \frac{\partial u}{\partial x_{i}} .
$$

Consider the equation

$$
L u(x)=f(x) .
$$

It is shown, under some general conditions on the coefficients of $L$, that if $f(x)$ is locally Hölder continuous and

$$
f(x)=O\left(|x|^{-2-\mu}\right) \text { as }|x| \longrightarrow \infty \quad(\mu>0)
$$

then there exists a bounded solution of (1.2) in $R^{n}$ when $n \geqq 3$. If $n=2$ then bounded entire solutions may not exist, but there exists a nonnegative solution of (1.2) in $R^{2}$ which is bounded above by $O(\log |x|)$. An application of these results to the Cauchy problem is given in the final section of the paper.

If in (1.3) $\mu=0$ then already the equation $\Delta u=f(n \geqq 3)$ may not have an entire bounded solution; an example is given by Meyers and Serrin [4].

2. Existence of a bouned solution. We shall need the following conditions:

$$
\sum_{i, j=l}^{n} a_{i j}(x) \xi_{j} \xi_{i}>0 \quad \text { if } x \in R^{n}, \xi \in R^{n}, \xi \neq 0,
$$

$a_{i j}(x), b_{i}(x)$ are bounded, locally Hölder continuous in $R^{n}$

$$
(1 \leqq i, j \leqq n)
$$

$$
\text { For some } \delta>0, R>0,0<\rho<1 \text {, }
$$

$$
(2+\delta)|x|^{-2} \sum_{i, i=i}^{n} a_{i j}(x) x_{i} x_{j} \leqq \rho \sum_{i=1}^{n} a_{i i}(x)+\sum_{i=1}^{n} x_{i} b_{i}(x) \text { if }|x|>R,
$$

$$
\sum_{i=1}^{n} a_{i i}(x) \geqq \gamma>0 \text { for all } x \in R^{n}
$$

$(\gamma$ constant)

Notice that (2.1) and (2.4) both follow from the condition of uniform ellipticity

$$
\sum_{i, j=1}^{n} a_{i j}(x) \xi_{i} \xi_{j} \geqq \gamma_{0}|\xi|^{2} \text { for all } x \in R^{n}, \xi \in R^{n}
$$

( $\gamma_{0}$ positive constant) 
Denote the eigenvalues of $\left(a_{i j}(x)\right)$ by $\lambda_{1}(x) \leqq \cdots \leqq \lambda_{n}(x)$. Then the condition in (2.3) means that

$$
(2+\delta) \tilde{\lambda}(x) \leqq \rho\left[\lambda_{1}(x)+\cdots+\lambda_{n}(x)\right]+\sum_{i=j}^{n} x_{i} b_{i}(x)
$$

for some $\lambda_{1}(x) \leqq \tilde{\lambda}(x) \leqq \lambda_{n}(x)$.

We finally impose on $f(x)$ the condition:

$$
f(x)=O\left(|x|^{-2-\nu}\right) \text { as }|x| \longrightarrow \infty \quad(\nu>0) \text {. }
$$

THEOREM 1. Suppose that either the conditions (2.1)-(2.4) or the conditions (2.5), (2.2) and (2.3) with $\rho=1$ hold. Then for any locally Hölder continuous function $f(x)$ satisfying (2.7) there exists a unique bounded solution $u(x)$ of (1.2) in $R^{n}$ satisfying $u(x) \rightarrow 0$ if $|x| \rightarrow \infty$.

Proof. We shall construct a function $v(r)$ for $r>R$ such that

$$
\begin{gathered}
L v(r) \leqq-|f(x)| \text { if } r=|x|>R, \\
v^{\prime}(r)<0 \text { if } r>R .
\end{gathered}
$$

It is easily seen that

$$
\begin{aligned}
L v(r)= & \frac{1}{r^{2}}\left[\sum_{i, j} a_{i j}(x) x_{i} x_{j}\right] v^{\prime \prime}(r) \\
& +\frac{v^{\prime}(r)}{r}\left[\sum_{i} a_{i i}(x)-\frac{1}{r^{2}} \sum_{i, j} a_{i j}(x) x_{i} x_{j}+\sum_{i} x_{i} b_{i}(x)\right] .
\end{aligned}
$$

If (2.9) holds then, by (2.3),

$$
\begin{gathered}
L v(r) \leqq\left[v^{\prime \prime}(r)+(1+\delta) \frac{v^{\prime}(r)}{r}\right] \frac{1}{r^{2}} \sum_{i, j} a_{i j}(x) x_{i} x_{j} \\
+\frac{(1-\rho) v^{\prime}(r)}{r} \sum_{i} a_{i i}(x) .
\end{gathered}
$$

Take $\mu>0$ such that $\mu<1, \mu<\nu, \mu \leqq \delta$ and take $0<R_{0}<R$. Consider the function

$$
v(r)=B \int_{r}^{\infty} \frac{d s}{s^{1+\mu}} \int_{R_{0}}^{\infty} \tau^{1+\mu} \frac{d \tau}{\tau^{2+\nu}}
$$

for any constant $B>0$. Then $v(r)$ satisfies (2.9), and

$$
\begin{gathered}
v^{\prime \prime}(r)+(1+\mu) \frac{v^{\prime}(r)}{r}=-\frac{B}{r^{2+\nu}}, \\
v^{\prime}(r)<-\frac{B C^{\prime}}{r^{1+\mu}}, \\
0<v(r)<\frac{B C}{r^{\mu}}
\end{gathered}
$$


if $r>R$, where $C^{\prime}, C$ are positive constants independent of $B$. Recalling (2.10) and assuming that (2.3), (2.4) hold, we get

$$
L v(r) \leqq-\frac{B C^{\prime}(1-\rho)}{r^{2+\mu}} \sum_{i} a_{i i}(x) \leqq-|f(x)| \text { if }|x|=r>R
$$

provided $B$ is sufficiently large. If instead of (2.3), (2.4) one assumes that (2.5) and (2.3) with $\rho=1$ hold, then again one derives from (2.10) the inequality $L v(r) \leqq-|f(x)|$.

Consider the exterior Dirichlet problem

$$
\begin{array}{cll}
L \phi_{0}(x)=f(x) & \text { in } & |x|>R, \\
\phi_{0}=0 & \text { on } & |x|=R, \\
\phi_{0}(x) \rightarrow 0 & \text { if } & |x| \rightarrow \infty
\end{array}
$$

In Meyers-Serrin [4] it is proved that there is a unioue solution $\phi_{0}$ of (2.12) if (2.7), (2.2) and (2.3) with $\rho=1$ hold, and if $\sum a_{i j}(x) x_{i} x_{i} \geqslant|x|^{2}$. The last condition is equivalent to the condition (2.5). The crucial step in the proof in [4] is the construction of $v(r)$ for which $L v(r) \leqq-|f(x)|$ and (2.11) holds. Since we have constructed such a $v(r)$ also when the assumptions (2.5), (2.3) with $\rho=1$ are replaced by (2.3), (2.4), the proof of [4] shows that the problem (2.12) has a unique solution $\phi_{0}$.

Consider next the Dirichlet problem

$$
\left\{\begin{array}{rll}
L \phi=0 & \text { in } & |x|>R, \\
\phi=h & \text { on } & |x|=R, \\
\phi(x) \rightarrow 0 & \text { if } & |x| \rightarrow \infty
\end{array}\right.
$$

where $h$ is a continuous function. This again has a unique solution $\phi$. Take $R^{\prime}>R$ and let $w$ be the soultion of

$$
\left\{\begin{aligned}
L w=0 & \text { in } \quad|x|<R^{\prime} \\
w=\phi & \text { on } \quad|x|=R^{\prime}
\end{aligned}\right.
$$

Finally let $w_{0}$ be the solution of

$$
\left\{\begin{array}{ccc}
L w_{0}(x)=f(x) & \text { in } \quad|x|<R^{\prime} \\
w_{0}=\phi_{0} & \text { on } \quad|x|=R^{\prime}
\end{array}\right.
$$

Then $\dot{\phi}+\phi_{0}$ and $w+w_{0}$ are solutions of $L u=f$ in $|x|>R$ and $|x|<R^{\prime}$ respectively, and they coincide on $|x|=R^{\prime}$. If there exists a function $h$ such that

$$
\phi+\phi_{0}=w+w_{0} \text { on }|x|=R,
$$

then $\phi+\phi_{0}=w+w_{0}$ in $R<|x|<R^{\prime}$, so that 


$$
u(x)=\left\{\begin{array}{ccc}
\phi+\phi_{0} & \text { in } & |x|>R, \\
w+w_{0} & \text { in } & |x|<R^{\prime}
\end{array}\right.
$$

defines a bounded solution of (1.2) in $R^{n}$ which tends to zero as $|x| \rightarrow \infty$.

Denote by $X$ the Banach space of continuous functions on $|x|=R$ with the sup norm, and denote by \|\| the norm of operators in $X$. Denote by $W h$ the restriction of $w$ to $|x|=R$. Then (2.16) reduces to

$$
h-W h=w_{0}-\phi_{0} \text {. }
$$

If we show that

$$
\|W\|<1
$$

then the existence of a unique solution $h$ of (2.17) follows, and the existence part of the theorem is proved.

The function

$$
\tilde{\phi}(x)=\|h\| \frac{v(r)}{v(R)} \quad\left(\|h\|=\sup _{|x|=R}|h(x)|\right)
$$

satisfies:

$$
L \tilde{\phi} \leqq 0 \text { if }|x|>R, \tilde{\phi} \geqq \phi \text { if }|x|=R, \tilde{\phi}(x)-\phi(x) \rightarrow 0 \text { if }|x| \rightarrow \infty .
$$

By the maximum principle it follows that $\tilde{\phi} \geqq \phi$ if $|x|>$ R. Similarly $\tilde{\phi} \geqq-\phi$. Hence

$$
|\phi(x)| \leqq\|h\| \frac{v\left(R^{\prime}\right)}{v(R)}=\sigma\|h\| \quad \text { if } \quad|x|=R^{\prime},
$$

where $\sigma<1$ by (2.9). Since, by the maximum principle,

$$
\sup _{|x|=R}|w(x)| \leqq \sup _{|x|=R}|\phi(x)|,
$$

we conclude that

$$
\sup _{|x|=R}|w(x)| \leqq \sigma\|h\|
$$

This gives (2.18).

Suppose now that $\widetilde{u}(x)$ is another solution of (1.2) in $R^{n}$ which tends to zero as $|x| \rightarrow \infty$. We shall prove that $\tilde{u} \equiv u$. Let $z=u-\tilde{u}$ and denote by $h$ the restriction of $z$ to $|x|=R$. Then $W h=h$. Since $\|W\|<1, h=0$. It follows that $z \equiv 0$ in $R^{n}$.

From the proof of Theorem 1 we obtain the estimate

$$
u(x)=0\left(|x|^{-\mu}\right)
$$

on the solution. Hence: 
CoROLlaRY 1. Let the assumptions of Theorem 1 hold. Then for any number $N$ there is a unique solution of (1.2) in $R^{n}$ satisfying: $u(x) \rightarrow N$ if $|x| \rightarrow \infty$; further,

$$
u(x)=N+O\left(|x|^{-\mu}\right) \quad \text { as }|x| \rightarrow \infty
$$

for any $\mu \leqq \delta, \mu<\nu, \mu<1$.

Corollary 2. Suppose (2.1), (2.2) hold and suppose

$$
\begin{gathered}
|x| \sum_{i=1}^{n}\left|b_{i}(x)\right| \rightarrow 0 \text { if }|x| \rightarrow \infty, \\
\bar{a}_{i j}=\lim _{|x| \rightarrow \infty} a_{i j}(x) \text { exists for } 1 \leqq i, j \leqq n .
\end{gathered}
$$

If the matrix $\left(\bar{a}_{i j}\right)$ has at least three positive eigenvalues then the assertion of Theorem 1 and Corollary 1 are valid.

Proof. A nonsingular affine transformation $x \rightarrow T x$ does not change the assumptions and assertions of the corollary. Such a transformation changes $\left(a_{i j}\right)$ into $T\left(a_{i j}\right) T^{*}$. Thus, without loss of generality one may assume that

$$
\bar{\alpha}_{i j}=0 \quad \text { if } \quad i \neq j, \bar{a}_{i i}=1 \quad \text { if } i=1,2,3, a_{i i}=0 \quad \text { or } 1 \text { if } i \geqq 3 .
$$

But then the conditions (2.4), (2.3) (with $\rho=1$ ) are satisfied, so that Theorem 1 and Corollary 1 can be applied.

We recall a result of Gilbarg-Serrin [2; Theorem 3] asserting that if (2.2), (2.5), (2.21) hold, and if $n \geqq 3$ and

$$
\sum_{i}\left|b_{i}(x)\right|=O\left(\frac{1}{|x|}\right) \text { as }|x| \rightarrow \infty,
$$

then any bounded solution of $L u=0$ in $R^{n}$ has a limit at infinity. By the maximum principle, this yields a Liouville theorem: Any entire bounded solution of $L u=0$ is a constant. Hence:

Corollary 3. Suppose (2.1), (2.2), (2.20), (2.21) hold, and let the matrix $\left(\bar{\alpha}_{i j}\right)$ be nonsingular. Then, any bounded solution of (1.2) in $R^{n}, n \geqq 3$, has the form $N+u(x)$ where $u(x)$ is the solution asserted in Theorem 1. (Recall that $u(x)$ satisfies (2.19).)

3. The case $n=2$. If $(2.20),(2.21)$ hold and $n=2$, then the condition (2.3) with $\rho=1$ is not satisfied. We shall now study this situation. The following conditions will be imposed:

$$
n=2 \text { and for all } x \in R^{2}, \xi \in R^{2},
$$

$$
\sum_{i, j=1}^{2} a_{i j}(x) \xi_{i} \xi_{j} \geqq \nu_{0}|\xi|^{2} \quad\left(\nu_{0} \text { positive constant }\right),
$$




$$
\begin{array}{cc}
\sum_{i, j}\left|a_{i j}(x)-\bar{a}_{i j}\right| \leqq \frac{C}{(1+|x|)^{\kappa}} & (C>0, \kappa>0), \\
\sum_{j}\left|b_{i}(x)\right| \leqq \frac{C}{(1+|x|)^{1+\kappa}} & (C>0, \kappa>0),
\end{array}
$$

THEOREM 2. Let the conditions (2.2), (3.1)-(3.3) hold. Then for any locally Hölder continuous function $f(x)$ satisfying (2.7) there exists a solution $u(x)$ of (1.2) in $R^{2}$ satisfying

$$
0 \leqq u(x) \leqq K \log (2+|x|) \quad(K \text { constant }) .
$$

Proof. Without loss of generality we may assume that $\bar{a}_{i j}=$ $\delta_{i j}, 1 \leqq i, j \leqq 2$. We shall construct functions $v_{1}(r), v_{2}(r)$ for $r>R_{0}$ ( $R_{0}$ and fixed positive number) satisfying:

$$
\begin{aligned}
& \begin{cases}L v_{1}(r) \leqq 0 & \text { if } r \geqq R_{0}, \\
v_{1}\left(R_{0}\right)=0, v_{1}^{\prime}(r)>0 & \text { if } r>R_{0},\end{cases} \\
& \begin{cases}L v_{2}(r) \geqq 0 & \text { if } r \geqq R_{0}, \\
v_{2}\left(R_{0}\right)=0, v_{2}^{\prime}(r)>0 & \text { if } r>R_{0} .\end{cases}
\end{aligned}
$$

The inequality $L v_{1} \leqq 0$ is satisfied if

$$
v_{1}^{\prime \prime}+\frac{1}{r}\left(1+\frac{c}{r^{k}}\right) v_{1}^{\prime}=0, \quad v_{1}^{\prime}>0
$$

where $c$ is a sufficiently large positive constant. A solution of (3.7) which vanishes at $r=R_{0}$ is given by

$$
\begin{aligned}
v_{1}(r) & =\int_{R_{0}}^{r} \exp \left\{-\int_{R_{0}}^{t} \frac{c}{s^{1+\kappa}} d s\right\} \frac{d t}{t} \\
& =\int_{R_{0}}^{r} \exp \left\{\frac{c}{\kappa}\left(t^{-\kappa}-R_{0}^{-\kappa}\right)\right\} \frac{d t}{t} .
\end{aligned}
$$

This function then satisfies (3.5). Similarly,

$$
v_{2}(r)=\int_{R_{0}}^{r} \exp \left\{-\frac{c}{\kappa}\left(t^{-\kappa}-R_{0}^{-\kappa}\right)\right\} \frac{d t}{t}
$$

is a solution of (3.6). From (3.8), (3.9) it is clear that

$$
c_{1} \log (1+r) \leqq v_{1}(r) \leqq v_{2}(r) \leqq c_{2} \log (1+r) \quad\left(c_{1}>0, c_{2}>0\right)
$$

for all $r \geqq R_{0}+1$.

For each $R>R_{0}+1$, let $u_{R}$ be the solution of

$$
\begin{aligned}
L u_{R} & =0 & & \text { in } R_{0}<|x|<R, \\
u_{R} & =0 & & \text { on }|x|=R_{0}, \\
u_{R} & =v_{2}(R) & & \text { on }|x|=R .
\end{aligned}
$$


From the maximum principle it follows that $u_{R} \geqq v_{2}$ if $R_{0}<|x|<R$. From (3.10) we have:

$$
u_{R} \leqq \frac{c_{2}}{c_{1}} v_{1}(R) \quad \text { on }|x|=R .
$$

Hence, by the maximum principle,

$$
u_{R} \leqq \frac{c_{2}}{c_{1}} v_{1} \quad \text { if } R_{0}<|x|<R .
$$

Using (3.10) once more we conclude that

$$
c_{1} \log (1+r) \leqq u_{R}(x) \leqq \frac{c_{2}}{c_{1}} c_{2} \log (1+r) \quad \text { if } R_{0}+1 \leqq|x|<R .
$$

We can now take a subsequence $\left\{u_{R_{m}}\right\}$, with $R_{m} \rightarrow \infty$ if $m \rightarrow \infty$, that is uniformly convergent in compact subsets of $\left\{x ;|x| \geqq R_{0}\right\}$ to a solution $w_{2}(x)$ of

$$
\left\{\begin{aligned}
L w_{2}=0 & \text { if } R_{0}<|x|<\infty \\
w_{2}=0 & \text { on }|x|=R_{0}
\end{aligned}\right.
$$

and

(3.12) $\quad c_{1} \log (1+r) \leqq w_{2}(x) \leqq \frac{c_{2}}{c_{1}} c_{2} \log (1+r) \quad\left(r=|x|>R_{0}+1\right)$.

Let $R^{\prime}=R_{0}, R^{\prime \prime}>R^{\prime}$ and denote by $S^{\prime}$ and $S^{\prime \prime}$ the circles given by $|x|=R^{\prime}$ and $|x|=R^{\prime \prime}$ respectively. Let $w_{1}$ be the unique solution (see [4]) of

$$
\left\{\begin{array}{l}
L w_{1}=f \quad \text { in }|x|>R^{\prime}, \\
w_{1}=0 \text { on } S^{\prime}, \\
w_{1} \text { bounded in }|x|>R^{\prime} .
\end{array}\right.
$$

Let $z_{1}$ and $z_{2}$ be the solutions of

$$
\begin{aligned}
& \left\{\begin{array}{cl}
L z_{1}=f & \text { in }|x|<R^{\prime \prime}, \\
z_{1}=w_{1} & \text { on } S^{\prime \prime},
\end{array}\right. \\
& \left\{\begin{array}{cl}
L z_{2}=0 & \text { in }|x|<R^{\prime \prime}, \\
z_{2}=w_{2} & \text { on } S^{\prime \prime} .
\end{array}\right.
\end{aligned}
$$

Denote by $z_{1}^{*}, z_{1}^{*}$ the restriction to $S^{\prime}$ of $z_{1}$ and $z_{2}$, respectively.

We shall introduce now an operator $W$ similar to the operator $W$ in the proof of Theorem 1 . We denote by $X$ the Banach space of the continuous functions $h$ on $S^{\prime}$ provided with the uniform norm. For any $h \in X$, let $w$ be the unique solution (see [4]) of 


$$
\left\{\begin{array}{l}
L w=0 \quad \text { in }|x|>R^{\prime}, \\
w=h \quad \text { on } S^{\prime}, \\
w \text { bounded in }|x| \geqq R^{\prime},
\end{array}\right.
$$

and let $z$ be the solution of

$$
\left\{\begin{aligned}
L z=0 & \text { in }|x|<R^{\prime \prime} \\
z=w & \text { on } S^{\prime \prime}
\end{aligned}\right.
$$

Then $W h$ is defined as the restriction of $z$ to $S^{\prime}$.

By the maximum principle, for any $\varepsilon>0$,

$$
\|h\|+\varepsilon v_{1}(r) \geqq \pm w(x) \quad \text { in }|x|>R^{\prime} .
$$

This implies that

$$
\sup _{|x|=R^{\prime \prime}}|w(x)| \leqq\|h\|
$$

Again by the maximum principle,

$$
\sup _{|x|=R^{\prime}}|z(x)| \leqq \sup _{|x|=R^{\prime \prime}}|z(x)|=\sup _{|x|=R^{\prime \prime}}|w(x)| \text {. }
$$

Hence, $\|W h\| \leqq\|h\|$. Since, for $h(x) \equiv 1, W h=h$, it follows that $\|W=\| 1$.

Employing the function $v_{1}(r)$ and using the maximum principle it can be shown (see [4, p. 523]) that Liouville's theorem is valid (under the assumptions of Theorem 2), that is, every bounded solution $u$ of $L u=0$ in $R^{2}$ is a constant. Now, $h$ satisfies $W h=h$ if and only if the corresponding $w$ and $z$ coincide on $S^{\prime}, S^{\prime \prime}$ and, consequently, in the region $R^{\prime}<|x|<R^{\prime \prime}$; thus, $W h=h$ if and only if the pair $w, z$ defines a bounded entire solution $u$ of $L u=0$. By Liouville's theorem it follows that $u \equiv$ const. and, in particular, $h=$ const. Thus, 1 is an eigenvalue of $W$ and the eigenspace is one dimensional.

From the interior Schauder estimates (see, for instance, [1]) one deduces that $W$ maps bounded subsets of $X$ into compact subsets. Hence the Fredholm-Riesz-Schauder theorem can be applied to solve equations of the form

$$
\zeta+W h=h .
$$

Denoting by $\hat{h}$ an eigenfunctional of the adjoint $W^{*}$ of $W$, we can assert that the equation (3.18) has a solution if and only if

$$
\hat{h}(\zeta)=0 .
$$

We wish to solve the equation 


$$
z_{1}^{*}+\lambda z_{2}^{*}+W h=h
$$

for some real number $\lambda$. We first show that

$$
\hat{h}\left(z_{2}^{*}\right) \neq 0 \text {. }
$$

Suppose $\hat{h}\left(z_{2}^{*}\right)=0$. Then the equation

$$
z_{2}^{*}+W h=h
$$

has a solution $h$. Denote by $w, z$ the corresponding solutions of (3.16), (3.17). Then the functions $w+w_{2}$ and $z+z_{2}$ coincide on $S^{\prime \prime}$ and (by (3.21)) on $S^{\prime}$. Since they both are solutions of $L u=0$ in $R^{\prime}<|x|<R^{\prime \prime}$, it follows that they coincide in this region. Consequently, the function

$$
u_{0}(x)=\left\{\begin{array}{cl}
w(x)+w_{2}(x) & \text { if }|x|>R^{\prime} \\
z(x)+z_{2}(x) & \text { if }|x|<R^{\prime \prime}
\end{array}\right.
$$

is an entire solution of $L u_{0}=0$. Since, by $(3.12), u_{0}(x) \rightarrow \infty$ if $|x| \rightarrow \infty, u_{0}$ must attain a minimum at some point in $R^{2}$. But then, by the maximum principle, $u_{0}(x) \equiv$ const.; this is impossible since $u_{0}(x) \rightarrow \infty$ if $|x| \rightarrow \infty$.

Having proved (3.20), we choose in (3.19)

$$
\lambda=-\hat{h}\left(z_{1}^{*}\right) / \hat{h}\left(z_{2}^{*}\right) \text {. }
$$

Then

$$
\hat{h}\left(z_{1}^{*}+\lambda z_{1}^{*}\right)=0
$$

consequently (3.19) has a solution which we shall denote by $h$. Denote by $w, z$ the solutions of (3.16), (3.17) corresponding to this $h$. The functions

$$
w+w_{1}+\lambda w_{2}, \quad z+z_{1}+\lambda z_{2}
$$

are solutions of $L u=f$ in $|x|>R^{\prime}$ and $|x|<R^{\prime \prime}$ respectively. They coincide on $S^{\prime \prime}$ and (by 3.19 )) on $S^{\prime}$; consequently, they coincide in $R^{\prime}<|x|<R^{\prime \prime}$. The function

$$
\hat{u}(x)= \begin{cases}w(x)+w_{1}(x)+\lambda w_{2}(x) & \text { if }|x|>R^{\prime}, \\ z(x)+z_{1}(x)+\lambda z_{2}(x) & \text { if }|x|<R^{\prime \prime}\end{cases}
$$

is then an entire solution of $L \hat{u}=f$. In view of (3.12), the function $u(x)=\hat{u}(x)+K_{0}$ is a solution of (1.2) in $R^{2}$, satisfying (3.4), provided $K_{0}$ is a sufficiently large positive constant.

REMARK. If $L=\Delta$ then for any locally Hölder continuous function $f(x)$ with compact support $K$ for which 


$$
\Phi \equiv \int_{K} f(x) d x \neq 0
$$

there does not exist a bounded entire solution of $L v=f$ in $R^{2}$. Indeed, suppose $\Phi>0$ and let

$$
w(x)=\frac{1}{2 r} \int_{K} f(y) \log |x-y| d y .
$$

Then $\Delta w=f$ in $R^{2}$ and

$$
w(x)=\frac{\Phi}{2 \pi} \log |x|+O(1) \quad \text { if } x \rightarrow \infty .
$$

If there is a bounded entire solution $v(x)$ of $\Delta v=f$ in $R^{2}$ then the function $u=w-v$ is harmonic in $R^{2}$ and $u(x) \rightarrow \infty$ if $x \rightarrow \infty$. Consequently $u$ must attain its minimum (in $R^{2}$ ) at a finite point. By the maximum principle, $u(x) \equiv$ const., which is impossible.

4. An application. Consider the Cauchy problem

$$
\begin{gathered}
\frac{\partial u}{\partial t}=\Delta u+\sum_{i=l}^{n} a_{i}(x) \frac{\partial u}{\partial x_{i}} \quad \text { if } 0<t<\infty, x \in R^{n} \\
u(0, x)=f(x) \text { if } x \in R^{n} .
\end{gathered}
$$

We shall assume: $a_{i}(x)$ are locally Hölder continuous and

$$
\left|a_{i}(x)\right| \leqq \frac{A}{(1+|x|)^{2+\nu}} \quad(\nu>0, A>0),
$$

$f(x)$ is continuous and

$$
|f(x)-f(y)| \leqq N|x-y|
$$

It is then well known [1] that the problem (4.1), (4.2) has a unique solution in the class of functions $v(t, x)$ satisfying, for each $T>0$,

$$
|v(t, x)| \leqq C e^{c|x|^{2}} \quad\left(0 \leqq t \leqq T, x \in R^{n}\right)
$$

for some positive constants $C, c$ depending on $v, T$.

THEOREM 3. Let (4.3), (4.4) hold, and let $n \geqq 3$. Then the solution $u(t, x)$ of (4.1), (4.2) satisfies

$$
\left|u(t, x)-\frac{1}{(4 \pi t)^{n / 2}} \int_{R^{n}} \exp \left\{-\frac{|x-\xi|^{2}}{4 t}\right\} f(\xi) d \xi\right| \leqq M
$$

for all $t \geqq 0, x \in R^{n}$ where $M$ is a constant.

Proof. We can write $u(t, x)$ in the form (see [3]) 


$$
u(t, x)=E f\left(\xi_{x}(t)\right)
$$

where $E$ is the expectation and $\xi_{x}(t)$ is a solution of the stochastic integral equation

$$
\xi_{x}(t)=x+\int_{0}^{t} a\left(\xi_{x}(s)\right) d s+2 \int_{0}^{t} d w(s) ;
$$

here $w(t)$ is $n$-dimentional Brownian motion. Similarly (for $a_{i} \equiv 0$ )

$$
\frac{1}{(4 \pi t)^{n / 2}} \int_{R^{n}} \exp \left\{-\frac{|x-\xi|^{2}}{4 t}\right\} f(\xi) d \xi=E f(x+2 w(t)) .
$$

By Theorem 1 there exists a bounded solution $v_{j}(x)$ of

$$
\Delta v_{j}+\sum_{i=1}^{n} a_{i}(x) \frac{\partial v_{j}}{\partial x_{i}}=\left|a_{j}(x)\right| \text { in } R^{n} .
$$

By Ito's formula [3],

$$
E \int_{0}^{t}\left|a_{j}\left(\xi_{x}(s)\right)\right| d s=E v_{j}\left(\xi_{x}(t)\right)-v_{j}(x)
$$

Hence,

$$
E\left|\int_{0}^{t} a_{j}\left(\xi_{x}(s)\right) d s\right| \leqq C
$$

where $C$ is a constant independent of $(t, x)$. Recalling (4.7), we conclude that

$$
E\left|\xi_{x}(t)-x-2 w(t)\right| \leqq C .
$$

Combining (4.6), (4.8) with (4.4), (4.9), the assertion of the theorem follows.

For $n=2$ one can employ Theorem 2 and establish the inequality

$$
\left|u(t, x)-\frac{1}{(4 \pi t)^{1 / 2}} \int_{R^{2}} \exp \left\{-\frac{|x-\xi|^{2}}{4 t}\right\} f(\xi) d \xi\right| \leqq M \log (2+t+|x|) .
$$

\section{REFERENCES}

1. A. Friedman, Partial Differential Equations of Parabolic Type, Prentice-Hall Englewood Cliffs, N. J., 1964.

2. D. Gilbarg and J. Serrin, On isolated singularities of solutions of second order elliptic equations, J. D'Analyse Mathematique, 4 (1954-6), 309-340.

3. I I. Gikhman and A. V. Skorokhod, Introduction to the Theory of Random Process, W. B. Saunders Company, Philadelphia, 1969.

4. N. Meyers and J. Serrin, The exterior Dirichlet problem for second order elliptic differential equations, J. Math. and Mech., 9 (1960), 513-538.

Received October 15, 1971. This work is partially supported by NSF grant GP-28484. 



\section{PACIFIC JOURNAL OF MATHEMATICS}

\section{EDITORS}

\section{H. SAMELSON}

Stanford University

Stanford, California 94305

C. R. Новву

University of Washington Seattle, Washington 98105

\section{J. DuGundJI}

Department of Mathematics University of Southern California Los Angeles, California 90007

RICHARD ARENS

University of California Los Angeles, California 90024

\section{ASSOCIATE EDITORS}
E. F. BECKENBACH
B. H. NeumanN
F. WOLF
K. YoSHIDA

\section{SUPPORTING INSTITUTIONS}

\author{
UNIVERSITY OF BRITISH COLUMBIA \\ CALIFORNIA INSTITUTE OF TECHNOLOGY \\ UNIVERSITY OF CALIFORNIA \\ MONTANA STATE UNIVERSITY \\ UNIVERSITY OF NEVADA \\ NEW MEXICO STATE UNIVERSITY \\ OREGON STATE UNIVERSITY \\ UNIVERSITY OF OREGON \\ OSAKA UNIVERSITY
}

\author{
UNIVERSITY OF SOUTHERN CALIFORNIA \\ STANFORD UNIVERSITY \\ UNIVERSITY OF TOKYO \\ UNIVERSITY OF UTAH \\ WASHINGTON STATE UNIVERSITY \\ UNIVERSITY OF WASHINGTON \\ $*{ }^{*}$
AMERICAN MATHEMATICAL SOCIETY
NAVAL WEAPONS CENTER
}

The Supporting Institutions listed above contribute to the cost of publication of this Journal, but they are not owners or publishers and have no responsibility for its content or policies.

Mathematical papers intended for publication in the Pacific Journal of Mathematics should be in typed form or offset-reproduced, (not dittoed), double spaced with large margins. Underline Greek letters in red, German in green, and script in blue. The first paragraph or two must be capable of being used separately as a synopsis of the entire paper. The editorial "we" must not be used in the synopsis, and items of the bibliography should not be cited there unless absolutely necessary, in which case they must be identified by author and Journal, rather than by item number. Manuscripts, in duplicate if possible, may be sent to any one of the four editors. Please classify according to the scheme of Math. Rev. Index to Vol, 39. All other communications to the editors should be addressed to the managing editor, Richard Arens, University of California, Los Angeles, California, 90024.

50 reprints are provided free for each article; additional copies may be obtained at cost in multiples of 50 .

The Pacific Journal of Mathematics is issued monthly as of January 1966. Regular subscription rate: $\$ 48.00$ a year (6 Vols., 12 issues). Special rate: $\$ 24.00$ a year to individual members of supporting institutions.

Subscriptions, orders for back numbers, and changes of address should be sent to Pacific Journal of Mathematics, 103 Highland Boulevard, Berkeley, California, 94708.

PUBLISHED BY PACIFIC JOURNAL OF MATHEMATICS, A NON-PROFIT CORPORATION

Printed at Kokusai Bunken Insatsusha (International Academic Printing Co., Ltd.), 270, 3-chome Totsuka-cho, Shinjuku-ku, Tokyo 160, Japan. 


\section{Pacific Journal of Mathematics}

\section{Vol. 44, No. $2 \quad$ June, 1973}

Tsuyoshi Andô, Closed range theorems for convex sets and linear liftings . . . . . . 393

Richard David Bourgin, Conically bounded sets in Banach spaces . . . . . . . . . 411

Robert Jay Buck, Hausdorff dimensions for compact sets in $R^{n} \ldots \ldots \ldots \ldots \ldots \ldots . \ldots 421$

Henry Cheng, A constructive Riemann mapping theorem ................ 435

David Fleming Dawson, Summability of subsequences and stretchings of

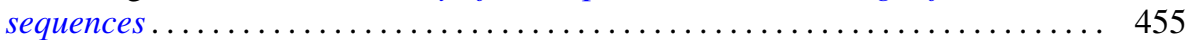

William Thomas Eaton, A two sided approximation theorem for 2-spheres ....... 461

Jay Paul Fillmore and John Herman Scheuneman, Fundamental groups of compact complete locally affine complex surfaces ....................... 487

Avner Friedman, Bounded entire solutions of elliptic equations . . . . . . . . . . . 497

Ronald Francis Gariepy, Multiplicity and the area of an $(n-1)$ continuous

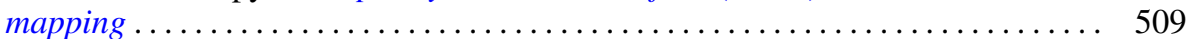

Andrew M. W. Glass, Archimedean extensions of directed interpolation groups . . . . 515

Morisuke Hasumi, Extreme points and unicity of extremum problems in $H^{1}$ on

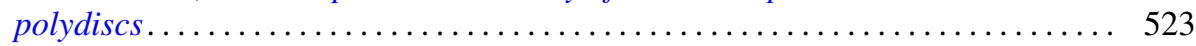

Trevor Ongley Hawkes, On the Fitting length of a soluble linear group . . . . . . 537

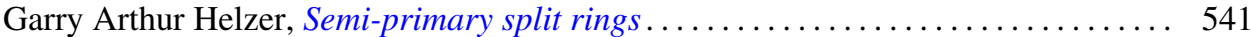

Melvin Hochster, Expanded radical ideals and semiregular ideals . . . . . . . . . 553

Keizō Kikuchi, Starlike and convex mappings in several complex variables . . . . . . 569

Charles Philip Lanski, On the relationship of a ring and the subring generated by its

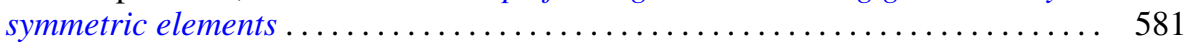

Jimmie Don Lawson, Intrinsic topologies in topological lattices and semilattices ........................................... 593

Roy Bruce Levow, Counterexamples to conjectures of Ryser and de Oliveira ...... 603

Arthur Larry Lieberman, Some representations of the automorphism group of an infinite continuous homogeneous measure algebra ..........

William George McArthur, $G_{\delta}$-diagonals and metrization theorems $\ldots .$.

James Murdoch McPherson, Wild arcs in three-space. II. An invariant of

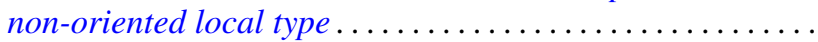

H. Millington and Maurice Sion, Inverse systems of group-valued measures ...

C. Edward Moore, Concrete semispaces and lexicographic separation of convex

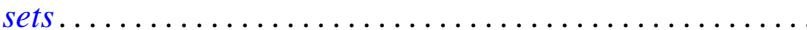

Jingyal Pak, Actions of torus $T^{n}$ on $(n+1)$-manifolds $M^{n+1}$.

Merrell Lee Patrick, Extensions of inequalities of the Laguerre and Turán type . . . . 675

Harold L. Peterson, Jr., Discontinuous characters and subgroups of finite index. . . . 683

S. P. Philipp, Abel summability of conjugate integrals . . . . . . . . . . . . . 693

R. B. Quintana and Charles R. B. Wright, On groups of exponent four satisfying an

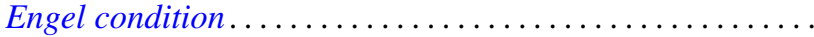

Marlon C. Rayburn, On Hausdorff compactifications. . . . . . . . . .

Martin G. Ribe, Necessary convexity conditions for the Hahn-Banach theorem in

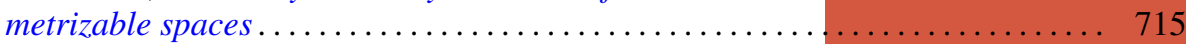

Ryōtarō Satō, On decomposition of transformations in infinite measure spaces .... 733

Peter Drummond Taylor, Subgradients of a convex function obtained from a

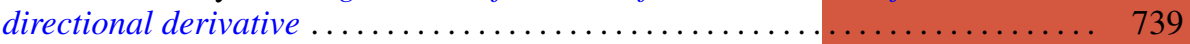

James William Thomas, A bifurcation theorem for $k$-set contractions . . . . . . . . 749 Clifford Edward Weil, A topological lemma and applications to real functions . . . . 757

Stephen Andrew Williams, A nonlinear elliptic boundary value problem . . ....... 767

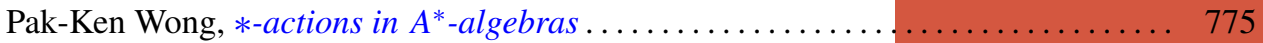

